\title{
RECUPERAÇÃO DE CLONES DE CAFEEIRO CONILON VARIEDADE "DIAMANTE ES8112" APÓS PERÍODO DE DÉFICIT HÍDRICO NO SOLO
}

\author{
André Alves Pinheiro ${ }^{1}$ \\ Wilian Rodrigues Ribeiro² \\ Daniel Ferreira Soares ${ }^{3}$ \\ Melissa Alvarenga de Oliveira ${ }^{4}$ \\ Camila Aparecida da Silva Martins ${ }^{5}$ \\ Edvaldo Fialho dos Reis $^{6}$
}

Resumo: Um dos principais fatores limitantes da cafeicultura é o déficit hídrico, portanto realizou-se estudos para quantificar a influência deste sobre a cultura e uma possível recuperação das plantas. Conduziu-se o experimento em um esquema fatorial $3 \times 2$, sendo 3 clones de cafeeiro conilon, variedade "Diamante ES8112", e déficit hídrico em 2 níveis, T0 - não sofrerá déficit hídrico e Td - déficit hídrico 30 dias após plantio até as plantas atingirem $10 \%$ da transpiração relativa do tratamento T0, num delineamento inteiramente casualizado, com 8 repetições, quantificando o número de folhas das plantas durante o período de experimento. Quando as plantas atingiram este patamar manteve-se 4 plantas por tratamento, as quais voltaram a ser irrigadas por 30 dias para avaliar a recuperação pós-estresse hídrico. Os clones apresentaram comportamentos diferentes em resposta à influência do déficit hídrico e quanto à capacidade de recuperação após o período de deficiência hídrica no solo.

Palavras-chave: Café; Estresse Hídrico; Desenvolvimento Inicial; Número de Folhas.

\footnotetext{
1 Graduando em Agronomia da Universidade Federal do Espírito Santo - UFES, Brasil. E-mail: aalvespinheiro7@gmail.com.

2 Graduando em Agronomia da Universidade Federal do Espírito Santo - UFES, Brasil. E-mail: wilianrodrigues@msn.com.

3 Graduando em Agronomia da Universidade Federal do Espírito Santo - UFES, Brasil. E-mail: danielufes@live.com.

4 Graduanda em Agronomia da Universidade Federal do Espírito Santo - UFES, Brasil. E-mail: melissalvarengao@gmail.com.

5 Doutora e Professora da Universidade Federal do Espírito Santo - UFES, Brasil. E-mail: camila.cca@hotmail.com.

${ }^{6}$ Doutor e Professor da Universidade Federal do Espírito Santo - UFES, Brasil. E-mail: edreis@cca.ufes.br.
} 